\title{
Impaired Working Memory Duration But Normal Learning Abilities Found in Mice That Are Conditionally Deficient in the Close Homolog of L1
}

\author{
Stefan Kolata, ${ }^{1}$ Junfang Wu, ${ }^{3}$ Kenneth Light, ${ }^{1}$ Melitta Schachner, ${ }^{2,4}$ and Louis D. Matzel ${ }^{1}$ \\ ${ }^{1}$ Department of Psychology, and ${ }^{2}$ Cell Biology and Neuroscience, Rutgers, State University of New Jersey, Piscataway, New Jersey 08854, ${ }^{3}$ Department of \\ Neuroscience, Georgetown Medical Center, Washington, DC 20007, and ${ }^{4}$ Zentrum für Molekulare Neurobiologie, Universität Hamburg, D-20251 Hamburg, \\ Germany
}

In addition to its role in axon growth and neuronal migration, the close homolog of L1 (CHL1), a member of the L1 family of cell adhesion molecules, is involved in synaptic plasticity. To date, little has been done to disassociate the role of CHL1 during adulthood from its role during development. To address this issue, mice conditionally deficient in CHL1 (lacking CHL1 only after the third postnatal week) were tested relative to littermate controls as adults in five learning tasks and several tests of working memory (including duration and selective attention). CHL1-deficient mice showed no impairments in the learning tasks compared with wild-type controls. CHL1 deletion had no effect on selective attention despite its widespread impairment of working memory duration. These results suggest a role for CHL1 in the adult-brain in the short-term maintenance of information.

Key words: adhesion; knock-out mice; working memory; learning; memory; synaptic transmission; cognition; attention; selective attention; CHL1

\section{Introduction}

Cell adhesion molecules (CAMs) are crucial for cell-cell interactions and recognition. They have been implicated in numerous developmental functions including neural growth, migration and survival, as well as axon guidance and synaptic targeting (Maness and Schachner, 2007). In addition to their critical roles during the development of the nervous system, CAMs participate in synaptic plasticity and potentially learning.

While the roles L1 and other CAMs play in cognition have been investigated, the function of the close homolog of L1 (CHL1) has not been systematically assessed. There are reasons to believe, however, that CHL1 plays a role in cognition. In humans, alterations of the CHL1 gene are associated with some forms of mental retardation and schizophrenia (Angeloni et al., 1999; Sakurai et al., 2002; Frints et al., 2003). In animal studies, constitutively CHL1-deficient mice show alterations in cognitive ability including social behavior and sensorimotor gating (Pratte et al., 2003; Morellini et al., 2007).

To determine the potential role CHL1 plays in modulating cognitive abilities, in the present study, conditionally CHL1deficient mice were created. CHL1 was ablated only in excitatory neurons of the forebrain following the third postnatal week. Since

Received May 5, 2008; revised Sept. 24, 2008; accepted 0ct. 21, 2008.

This work was supported by National Institute on Aging Grants R01 AG029289 and AG022698, and the Busch Foundation.

Correspondence should be addressed to Louis D. Matzel, Department of Psychology, 152 Frelinghuysen Road, Rutgers University, Piscataway, NJ 08854. E-mail: matzel@rci.rutgers.edu.

D0I:10.1523/JNEUROSCI.2127-08.2008

Copyright $\odot 2008$ Society for Neuroscience $\quad$ 0270-6474/08/2813505-06\$15.00/0
CHL1 has been associated with a broad range of cognitive tasks, both the working memory (including selective attention and working memory duration) as well as general learning abilities were assessed.

\section{Materials and Methods \\ Subjects}

CHL1 floxed mice were mated to CaMkII cre mice to create CHL1 floxed/CaMKII mice that were conditionally deficient in CHL1 (Law et al., 2003, Bukalo et al., 2004). Tying the ablation of CHL1 gene to the activity of CaMKII allowed for the gene to be ablated only in the forebrain and hippocampus and only after the third postnatal week of life. In all, 13 such transgenic mice were created. These mice were compared with 7 C57BL/6 wild-type littermates. Animals were singly housed starting when they reached $80-86 \mathrm{~d}$ old. They were maintained on a $12 \mathrm{~h}$ light/ dark cycle.

\section{Learning tasks}

All animals were tested in five learning tasks, each of which engaged different learning domains. Briefly, in the Lashley III maze, animals rely on egocentric navigation strategies to locate food. In passive avoidance, animals learn to be passive to avoid aversive light and noise stimulation. In the spatial water maze, animals must integrate spatial information to efficiently locate a hidden platform in a pool of water. In odor discrimination, the animals discriminate and use a target odor to locate food. Finally, in associative fear conditioning, the animals learn to associate a tone with a shock. Training and testing in the apparatuses proceeded as specified in our previous papers describing the battery (Matzel et al., 2003, 2006; Kolata et al., 2005, 2007). For a more detailed description of the methods, see supplemental material, available at www.jneurosci.org.

Working memory tasks

Composite working memory. In this task, the animals had to perform simultaneously in two eight-arm radial mazes (RAM) located in the same 
room (see Fig. 2). Since both of these mazes shared overlapping spatial cues, the animals had to rely on working memory to retain where they had been in one maze while performing in the other maze and must simultaneously separate the relevance of room cues to performance in each of the two mazes. Although this task has previously been used to assess working memory capacity, it also places demands on other components of working memory, such as selective attention and working memory duration. The protocol for this procedure has been described previously (Kolata et al., 2005). For a more detailed description of the methods, see supplemental material, available at www.jneurosci.org.

Selective attention. Selective attention was assessed using an odormatch-to-sample procedure. As this procedure is novel, it will be described in detail.

The apparatus consisted of a hole-board with 16 evenly spaced holes elevated $5.5 \mathrm{~cm}$ above the floor of an open field. Food cups, containing a layer of odorant (spices) covered by a wire mesh and wood chip bedding, were located under four of these holes. The animals were initially trained to locate buried food (chocolate puffed rice). Following this, they were trained in an odor match-to-sample procedure. At the start of each trial, they were placed in a starting box $[29 \mathrm{~cm}$ (length) $\times 18 \mathrm{~cm}$ (width) $\times 13$ $\mathrm{cm}$ (height)], containing wood chip bedding and a food cup filled with a target odor (on the first two trials the cup also contained food). The mice were allowed $4 \mathrm{~min}$ of exposure to the target in the starting box, and then were moved to the hole-board where they had to locate the cup containing the target odor. Digging at an incorrect cup was counted as an error. On each trial, there were three distracter cups, containing different odors and inaccessible food, and one target cup. Their location was changed after each trial to minimize the use of spatial cues. Across $5 \mathrm{~d}$, the animals received 3 trials a day with a $15 \mathrm{~min}$ ITI. At the conclusion of training the animals reached asymptotic performance.

After odor-match-to-sample training the animal's selective attention was assessed. During this phase, the ITI was shortened to $5 \mathrm{~min}$. On the first trial the target and distracter odors were novel. However, on the second trial the previously rewarded target cue became one of the distracters. This continued until all of the distracters were previously rewarded on recent trials. In this way demands on selective attention increased across trials, as previously rewarded odors became salient distracters. Finally, the selective attention demands were eliminated on a final trial when a new set of novel odors were introduced. All animals during this procedure received the same order of odor presentations because the animals showed no obvious preference for individual odors.

\section{Working memory duration: reinforced alternation}

In this task, animals had to choose between one of two arms that intersect to form the top of a "T." A food reinforcer was present in the end of one arm, and the location shifted to the alternate arm after a successful retrieval of food. Efficient performance required that animals alternate choices on successive trials. Training in this task proceeded as previously described (Kolata et al., 2007).

After all the animals were reliably performing this task, the short-term delay manipulation was introduced. On the first testing day the animals were allowed to make four alternations using a $20 \mathrm{~s}$ ITI before being held in the start box for $60 \mathrm{~s}$ before the fifth choice. This procedure was repeated for on the following day with the exception of the ITI increasing to $90 \mathrm{~s}$.

\section{Object recognition}

Animals tend to explore novel objects more then familiar objects. In this task the mice were first habituated to two objects. Then, following a delay, one of the objects was switched with a novel object. The amount time exploring the novel object was used as a measure of whether the animals could detect the change (i.e., maintain a memory of the original objects during the delay interval).

The animals were first habituated to two novel objects (a $24 \mathrm{oz}$ bottle filled with water dyed yellow and a small cup shaped like a bear) placed diagonally across from each other in an open field. The locations of the objects were counter-balanced to minimize the effects of spatial preferences. During habituation the animals freely explored the objects for $600 \mathrm{~s}$. The total amount of time the animal's nose came within $1 \mathrm{~cm}$ of the objects was recorded as exploration. The animals were then removed from the open field and placed back in their home cages for $300 \mathrm{~s}$. During this delay interval, one of the objects was replaced by a 12 oz soda can. Then animals were then placed back into the open field and allowed to explore for an additional $180 \mathrm{~s}$. Object recognition was assessed by comparing the novel object exploration during the object recognition phase to the exploration of the object in the same location during the habituation phase (last $180 \mathrm{~s}$ ).

\section{Tests of sensory/motor abilities}

Exploration and/or anxiety were measured in the open field test, the elevated plus maze, and the light/dark discrimination test. Motor ability and balance were measured using the balance beam, screen hang and balance pole tests. Pain sensitivity was measured using the hot plate test. The procedures for all of these tasks were conducted using the methods previously described (Matzel et al., 2003; Kolata et al., 2005, 2007). For a more detailed description of the methods, see supplemental material, available at www.jneurosci.org.

\section{Results}

\section{Learning performance}

Performance between groups in the five learning tasks (Lashley Maze, passive avoidance, odor discrimination, spatial water maze, and fear conditioning) was conducted using three 2-way ANOVAs comparing group times trial performance. For tasks with a single trial (i.e., passive avoidance and fear conditioning), independent $t$ tests were performed. There were no differences in learning found in any of the learning tasks (Fig. 1). In the Lashley Maze, Figure $1 A$, there was no main effect of group $\left(F_{(1,20)}=\right.$ $0.02, p=0.90)$, but a significant effect of trial, indicating that both groups showed learning across the six trials $\left(F_{(5,100)}=19.59\right.$, $p<0.001)$. The group times trial interaction was not significant $\left(F_{(5,100)}=0.578, p=0.72\right)$. In odor discrimination, Figure $1 B$, there was no main effect of group $\left(F_{(1,20)}=0.01, p=0.90\right)$, a significant effect of trial $\left(F_{(3,60)}=6.23, p<0.001\right)$, and no significant interaction $\left(F_{(3,60)}=0.53, p=0.66\right)$. Similarly in the water maze, Figure $1 C$, there was no group effect $\left(F_{(1,20)}=1.69\right.$, $p=0.21)$, but there was a significant trial effect $\left(F_{(9,180)}=13.157\right.$, $p<0.001)$. In the water maze probe trial, Figure $1 D$, the animals spent more time exploring the target quadrant in the first $30 \mathrm{~s}$ bin $\left(F_{(2,40)}=6.28, p<0.01\right)$. However, there was no group effect $\left(F_{(1,20)}=0.42, p=0.52\right)$, and no group times bin interaction $\left(F_{(2,40)}=0.74, p=0.48\right)$, and no group times trial interaction $\left(F_{(9,180)}=0.69, p=0.69\right)$. In passive avoidance, there was no difference between the groups in the ratio of the post-training step down latency to prestep training step down latency $\left(t_{(20)}=\right.$ $0.43, p=0.67$ ) (Fig. $1 E$ ). Similarly, there was no group difference in the ratio of the lick rate during the pre-CS-shock pairing to lick rate during post-CS-shock pairing in fear conditioning $\left(t_{(20)}=\right.$ $0.61, p=0.55)($ Fig. $1 F)$.

\section{Tests of sensory/motor fitness and exploration}

None of the tests of sensory and motor ability revealed differences between the CHL1 deficit mice and their wild-type littermates. Independent sample $t$ tests were performed comparing the two groups (hotplate test of pain sensitivity: $t_{(20)}=-0.37, p=0.71$; balance beam: $t_{(20)}=0.61, p=0.55$; screen hang: $t_{(20)}=-0.61$, $p=0.55$; balance pole: $\left.t_{(20)}=-0.32, p=0.75\right)$.

In the tests that measured exploratory behavior and/or anxiety, the results were more mixed. In the open field test, CHL1 deficit mice showed no differences in their percent time spent in the center of the field $\left(t_{(20)}=1.12, p=0.27\right)$, and no overall difference in total activity $\left(t_{(20)}=1.37, p=0.18\right)$. In the elevated plus maze there was no group differences in percent time spent in the open, more stressful, arms $\left(t_{(20)}=1.30, p=0.20\right)$ and no 

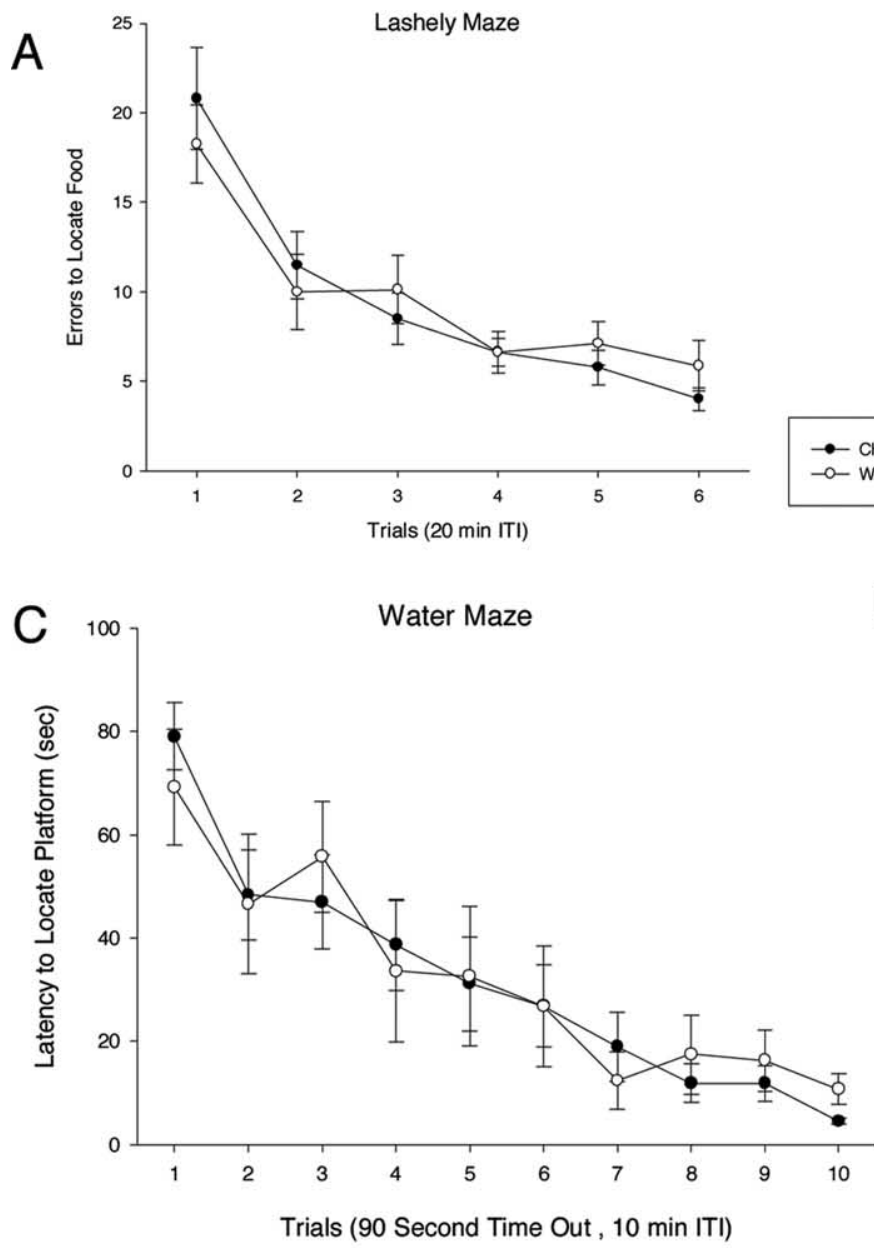

$E$

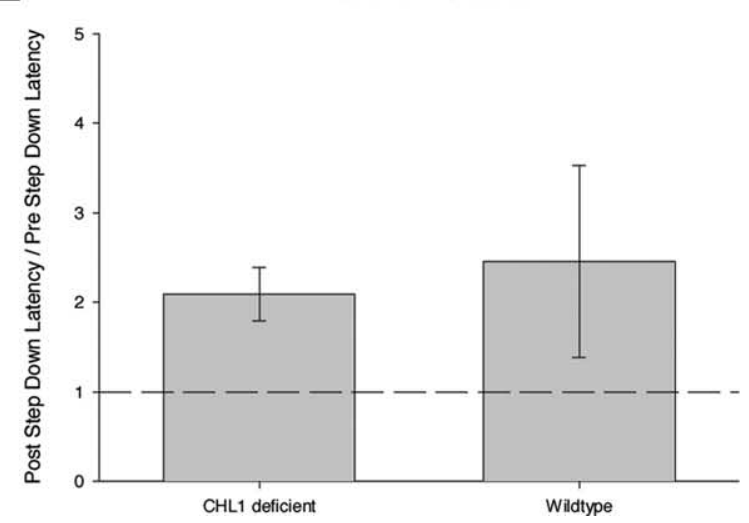

B

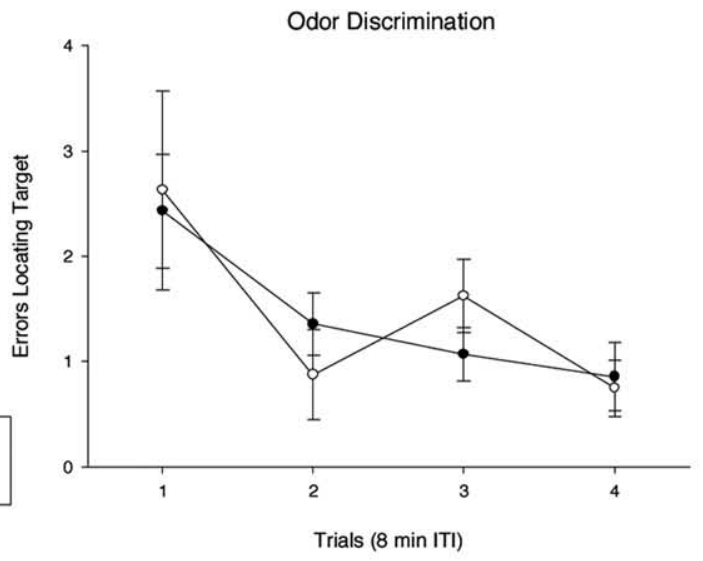

D

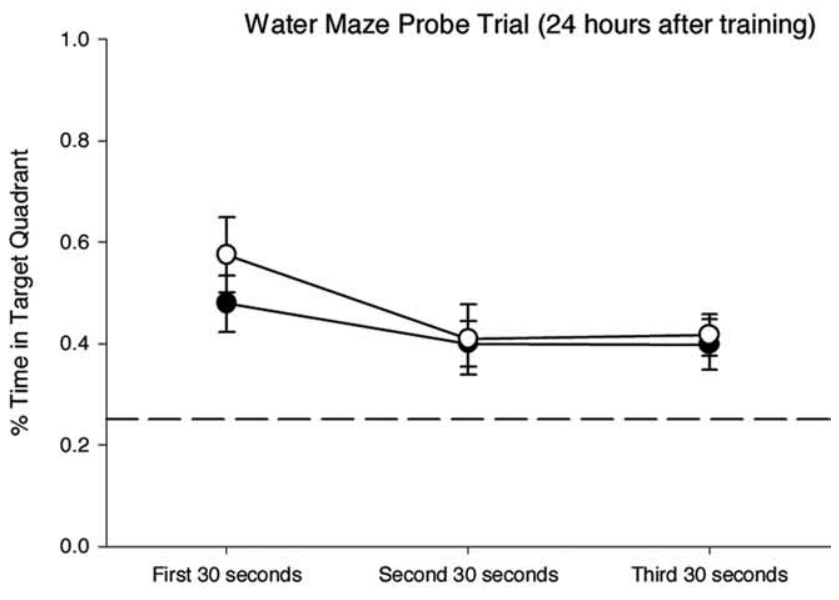

$\mathrm{F}$

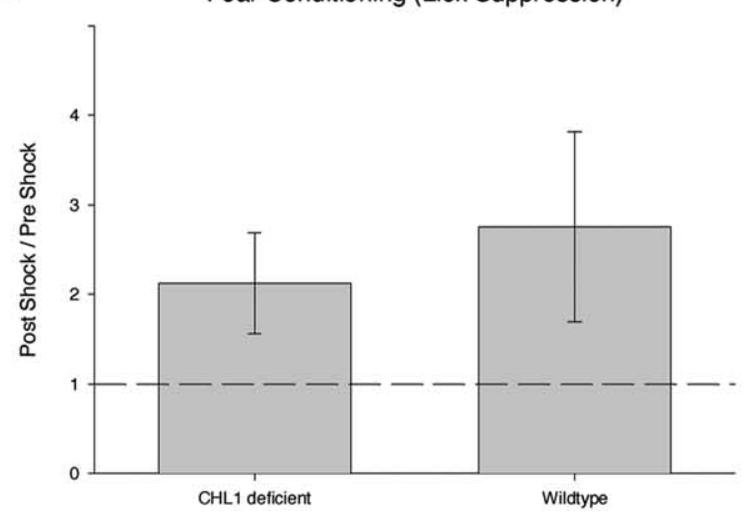

Figure 1. Performance of the CHL1-deficient mice and wild-type littermates in five learning tasks. No differences were found in the acquisition of these tasks. $\boldsymbol{A}$, Lashley Maze. $\boldsymbol{B}$, Odor discrimination. C, Spatial water maze. D, Ninety second water maze probe trial $24 \mathrm{~h}$ after training. $\boldsymbol{E}$, Passive avoidance. $\boldsymbol{F}$, Fear conditioning.

differences in latency to first enter the open arms $\left(t_{(20)}=0.59\right.$, $p=0.95)$. However, in the light/dark test the CHL1-deficient mice spent more time in the lighted part of the box, the part that is more stress provoking, then in the dark side of the box $\left(t_{(20)}=\right.$ 2.21, $p=0.04)$.

\section{Working memory ability: composite working memory task}

CHL1-deficient mice displayed impaired working memory ability during the concurrent radial arm maze task. Consistent with the other learning data, there were no differences in the learning rates between groups in either of the two radial arm mazes. A two-way ANVOA comparing the acquisition curves between the groups in the primary maze revealed a significant effect of trial $\left(F_{(7,133)}=8.26, p<0.001\right)$, but no effect of group $\left(F_{(1,19)}=0.38\right.$, $p=0.54)$ and no group times trial interaction $\left(F_{(7,133)}, p=0.94\right)$. A similar pattern of results was found in the secondary maze: an effect of trial $\left(F_{(4,76)}=12.36, p<0.001\right)$, no main effect of group $\left(F_{(1,19)}=0.01, p=0.92\right)$ and no group times trial interaction $\left(F_{(4,76)}=0.09, p=0.98\right)$. There was also no differences in the asymptotic levels of performance in either the primary maze, $t_{(19)}$ 


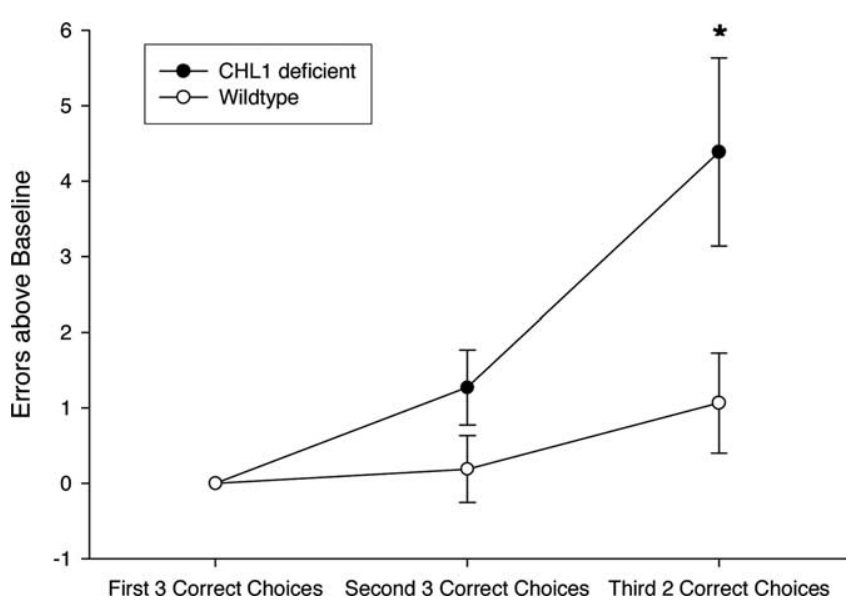

Figure 2. The animals had to perform simultaneously in two 8-arm RAM. They were allowed to make three correct choices in one RAM and then were moved to a second RAM, where they were again allowed to make three choices. This pattern repeated again with the next three choices and then the final two choices. Shown here are the performance levels in the second RAM compared with their baseline performance levels. CHL1-deficient mice were significantly worse on the final two choices, where working memory is most taxed.

$=-0.58, p=0.56(\mathrm{M}=3.62$ and SD of 1.43 for CHL1-deficient mice and $\mathrm{M}=3.04$ and SD of 2.06 for wild type) or secondary maze $\left(t_{(19)}=-0.25, p=0.80\right)(\mathrm{M}=3.75$ and $\mathrm{SD}$ of 2.01 for CHL1-deficient mice and $\mathrm{M}=3.69$ and SD of 1.55 for wild type). After reaching asymptotic levels of performance in both mazes, the animals were subjected to a working memory manipulation in which they had to make alternating groups of choices in the two mazes. Figure 2 shows their performance in the secondary maze (relative to baseline performance in the same maze). A two-way ANVOA revealed that both groups showed significantly worse performance in later choices in which the mice were under increased working memory demands $\left(F_{(2,19)}=6.79, p<0.001\right)$. However, the CHL1-deficient mice showed significantly worse performance during this manipulation $\left(F_{(1,19)}=6.11, p<0.05\right)$. A post hoc planned comparisons revealed that the transgenic mice only differed on the number of errors to locate the final two baited arms, where working memory demands reached their apogee $\left(F_{(2,38)}=3.87, p<0.05\right)$.

\section{Selective attention in the odor match-to-sample task}

In this task, the animals had to ignore salient distracters that were rewarded on previous trials to correctly locate hidden food rewards, as such it primarily taxed selective attention. On the fourth test trial, the distracters were replaced with novel stimuli and the selective attention demands were thus eliminated. Figure 3 shows the animals performance during this task. As can be seen, the number of errors increased as the number of distracter increased, but decreased when the distracters were replaced by novel stimuli. A two-way mixed-measures ANOVA revealed a significant effect of trial $\left(F_{(3,60)}=7.75, p<0.001\right)$; however, the two groups did not differ $\left(F_{(1,20)}=0.001, p=0.98\right)$. A post hoc analysis using Tukey's honestly significant difference test revealed that on trial 4 , when selective attention demands were removed, errors were significantly lower from the preceding trial, where selective attention demands were high, but not different from the first trial where there was no demands placed on selective attention.

\section{Working memory duration}

In the two tests of working memory duration, the CHL1-deficient mice exhibited shorter durations then did their wild-type litter-

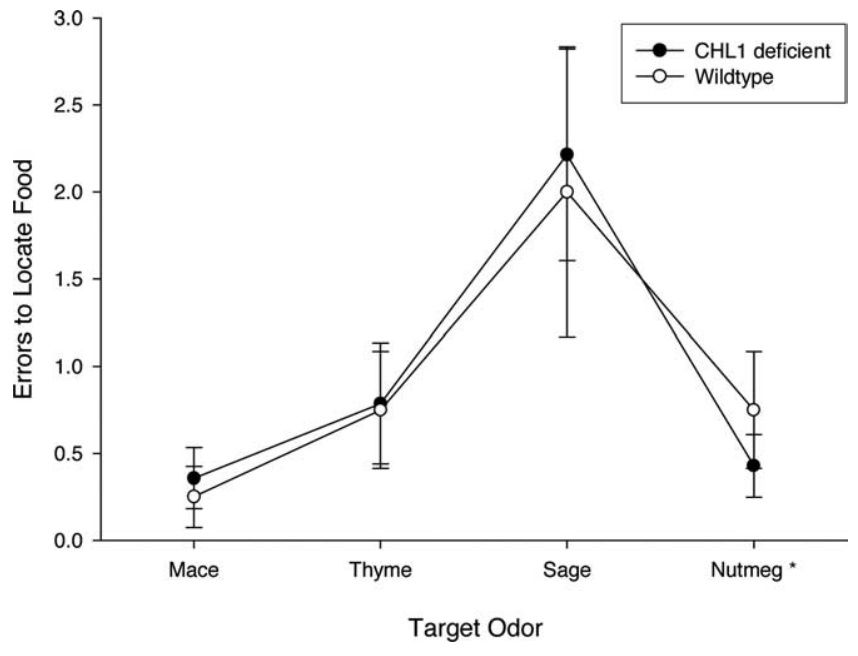

Figure 3. Comparison the CHL1-deficient mice and wild-type littermates in a selective attention task involving odor match-to-sample. The $x$-axis shows the target odors for each trial. On the first 3 trials, the previously rewarded odors (i.e., mace then mace and thyme) acted as distracters. Demands on selective attention increased across the first 3 trials. On the final trial, these demands were eliminated (novel odors were used). No differences were found.

mates. In the delayed reinforced alternation task, a $\chi^{2}$ test showed that the wild-type mice performed significantly above chance in selecting the correct arm after a 60 s delay $\left(\chi_{(1)}^{2}=4.5, p<0.01\right)$ but not after a $90 \mathrm{~s}$ delay $\left(\chi_{(1)}^{2}=0.5, p=0.47\right)$. However, the CHL1-deficient mice did not choose the correct arm significantly above chance level after either the 60 or $90 \mathrm{~s}$ delays $\left(60 \mathrm{~s}: \chi_{(1)}^{2}=\right.$ $0.00, p=1.0$; $90 \mathrm{~s}: \chi_{(1)}{ }_{(1)}=0.29, p=0.59$ ) (Fig. $4 A$ ). The groups did not differ on performance during the last 7 training trials with a 20 s delay (CHL1-deficient: $72 \%$ correct, $\chi_{(1)}^{2}=19.75, p<$ 0.01 ; wild type: $70 \%$ correct, $\chi_{(1)}^{2}=8.64, p<0.01$ ).

In the novel object recognition task, the CHL1-deficient mice tended to not explore the novel object following the delay as much as their wild-type littermates (Fig. 4B). A mixed measures two-way ANOVA comparing baseline levels of exploration to the exploration of the novel objects for both groups found an overall significant increase in exploration of the novel object $\left(F_{(1,19)}=\right.$ $6.63, p<0.05)$. However, there was no main effect of group $\left(F_{(1,19)}=0.02, p=0.87\right)$ and no significant interaction $\left(F_{(1,19)}=\right.$ $1.40, p=0.25)$. Post hoc planned comparisons revealed a significant increase in exploration of the novel object above baseline for the wild-type animals $\left(F_{(1,19)}=5.70, p<0.05\right)$. However, there was no significant increase found in the CHL1-deficient mice $\left(F_{(1,19)}=1.27, p=0.27\right)$.

\section{Discussion}

The CHL1-deficient mice revealed no learning or sensory/motor deficits in any of the tasks assessed here. Previously, impairments have been reported in constitutive CHL1-deficient mice, where these animals were found to have impaired spatial learning abilities, impaired motor abilities, and altered responses to sensory stimuli (Montag-Sallaz et al., 2002; Pratte, et a1., 2003; Morelliniet al., 2007). The intent of the present study was to determine CHL1's role in cognition independent of its developmental function. However, in light of the present findings, it may be inferred that these previously reported impairments are due to developmental abnormalities and are not the result of an intrinsic role of CHL1 in learning. While we cannot conclusively rule out procedural differences in accounting for the contrasting results, the tests reported here were clearly sensitive to differences in acqui- 
A

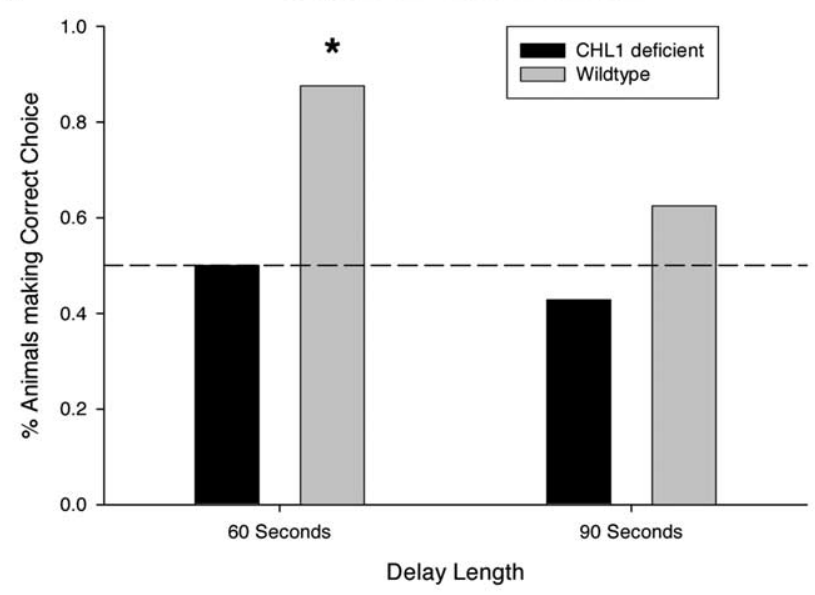

B

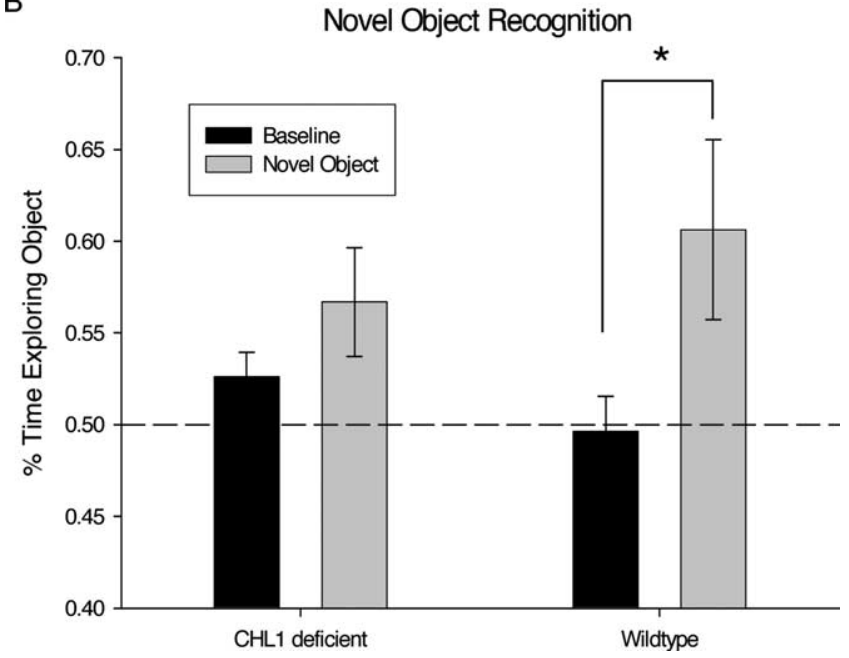

Figure 4. Performance of the CHL1-deficient mice and wild-type littermates on two tests of working memory duration. $A$, Delayed reinforced alternation. During the 60 s delay interval, the percentage of the wild-type but not the CHL1-deficient mice that made the correct choice was significantly above chance. At the $90 \mathrm{~s}$ delay, neither group was above chance. $\boldsymbol{B}$, In the novel object recognition task, the animals explored to two objects in an open field for 600 s. Then they were removed for $300 \mathrm{~s}$, during which time one of the objects was replaced. When the animals were reintroduced, only the wild-type mice explored the novel object at a level above their baseline exploration levels.

sitions and were not subject to artificial floor or ceiling constraints.

In marked contrast with the lack of learning impairments in CHL1-deficient mice, CHL1 ablation appears to alter aspects of working memory. Working memory is a limited capacity system that maintains and processes task relevant information, often under conditions of competing demands (Baddeley 1986). As such, working memory is thought to encompass both short-term information storage as well as other systems involved in active processing and integrating of information (Baddeley 1986). The present results suggest that CHL1 ablation selectively affects the working memory duration but does not seem to impair the processing components associated with working memory (e.g., selective attention).

The composite working memory abilities of the CHL1deficient mice were assessed in a task that involves all components of working memory. In this task, the animals had to maintain the memory of which arms they had visited in one radial arm maze while performing in a different radial arm maze task, stress- ing multiple aspects of working memory (e.g., working memory duration, capacity and selective attention). From this task alone, therefore, it would not be possible to precisely pinpoint the cause of the impairments seen the CHL1-deficient mice. To clarify the precise nature of the impairments further tests were performed to assess selective attention and working memory duration. While none of these subsequent tasks can be seen as "process-pure" (that is engaging only one aspect of working memory) they each place differential demands on either selective attention or working memory duration. Therefore, the results when taken holistically can isolate the impaired aspect of working memory.

The CHL1 mice did not show impairments in our test of selective attention. To efficiently perform this task the animals had to ignore the salient distracters and focus on the most recent sample odor. Therefore, it stressed selective attention but not working memory duration. The failure to find impairments in both selective attention abilities and general learning abilities is consistent with our previous studies showing that an association existed between these aspects of cognitive ability (Kolata et al., 2007).

In contrast with the lack of impairments found in the selective attention task, the CHL1-deficient mice displayed impaired working memory duration. The same patterns of results were found in both the delayed reinforced alternation and the novel object recognition task. In the reinforced alternation task, the transgenic mice were no better then chance in selecting the correct arm after only a 60 s delay, while the wild-type animals were well above chance at retention intervals of at least $90 \mathrm{~s}$. In the novel object recognition task after a delay of $300 \mathrm{~s}$, the wild-type mice, unlike the CHL1-deficient mice, explored the novel object more relative to their baseline exploration levels.

Our observations are interesting in view of recent observations that CHL1 is involved in synaptic vesicle recycling. It has been demonstrated that Hsc70, a synaptic vesicle chaperone, binds to the intracellular domain of CHL1 and cooperates with CHL1 in clathrin-mediated synaptic vesicle recycling (Leshchyns'ka et al., 2006). Proteins associated with the presynaptic machinery of vesicle release undergo substantial conformational changes during the process of exocytosis. CHL1 plays a beneficial role in renaturation of several components of the synaptic chaperone machinery including, Hsc70, CSP and "-SGT. Thus, CHL1 is crucial for efficient synaptic transmission. Interestingly, mice with constitutive genetic deficiency of CHL1 show reduced protein refolding activity. In addition, the machinery for synaptic vesicle exocytosis, in particular the SNARE complex, was unable to sustain prolonged synaptic activity. These observations suggest that the reduced working memory duration in conditionally ablated CHL1-deficient mice may be related to abnormalities in presynaptic functioning.

\section{References}

Angeloni D, Lindor NM, Pack S, Latif F, Wei MH, Lerman MI (1999) CALL gene is haploinsufficient in a 3p-syndrome patient. Am J Med Genet $86: 482-485$.

Baddeley AD (1986) Working memory. Oxford: Oxford UP.

Bukalo O, Fentrop N, Lee AY, Salmen B, Law JW, Wotjak CT, Schweizer M, Dityatev A, Schachner M (2004) Conditional ablation of the neural cell adhesion molecule reduces precision of spatial learning, long-term potentiation, and depression in the CAl subfield of mouse hippocampus. J Neurosci 24:1565-1577.

Frints SG, Marynen P, Hartmann D, Fryns JP, Steyaert J, Schachner M, Rolf B, Craessaerts K, Snellinx A, Hollanders K, D’Hooge R, De Deyn PP, Froyen G (2003) CALL interrupted in a patient with non-specific mental retardation: gene dosage-dependent alteration of murine brain development and behavior. Hum Mol Genet 12:1463-1474. 
Kolata S, Light K, Townsend DA, Hale G, Grossman HC, Matzel LD (2005) Variations in working memory capacity predict individual differences in general learning abilities among genetically diverse mice. Neurobiol Learn Mem 84:241-246.

Kolata S, Light K, Grossman HC, Hale G, Matzel LD (2007) Selective Attention is a primary determinant of the relationship between working memory and general learning ability in outbred mice. Learn Mem 14:22-28.

Law JW, Lee AY, Sun M, Nikonenko AG, Chung SK, Dityatev A, Schachner M, Morellini F (2003) Decreased anxiety, altered place learning, and increased CA1 basal excitatory synaptic transmission in mice with conditional ablation of neural cell adhesion molecule L1. J Neurosci 23:10419-10432.

Leshchyns'ka I, Sytnyk V, Richter M, Andreyeva A, Puchkov D, Schachner M (2006) The adhesion molecule CHL1 regulates uncoating of clathrincoated synaptic vesicles. Neuron 52:1011-1025.

Maness PF, Schachner M (2007) Neural recognition molecules of the immunoglobulin superfamily: signaling transducers of axon guidance and neuronal migration. Nat Neurosci 10:19-26.

Matzel LD, Han YR, Grossman H, Karnik MS, Patel D, Scott N, Specht SM, Gandhi CC (2003) Individual differences in the expression of a "general" learning ability in mice. J Neurosci 23:6423-6433.
Matzel LD, Townsend DA, Grossman H, Han YR, Hale G, Zappulla M, Light K, Kolata S (2006) Exploration in outbred mice covaries with general learning abilities irrespective of stress reactivity, emotionality and physical attributes. Neurobiol Learn Mem 82:228-240.

Montag-Sallaz M, Schachner M, Montag D (2002) Misguided axonal projections, neuronal cell adhesion molecule $180 \mathrm{~m}$ RNA upregulation, and altered behavior in mice deficient for the close homolog of L1. Mol Cell Biol 22:7967-7981.

Morellini F, Lepsveridze E, Kähler B, Dityatev A, Schachner M (2007) Reduced reactivity to novelty, impaired social behavior, and enhanced basal synaptic excitatory activity in perforant path projections to the dentate gyrus in young adult mice deficient in the neural cell adhesion molecule CHL1. Mol Cell Neurosci 34:121-136.

Pratte M, Rougon G, Schachner M, Jamon M (2003) Mice deficient for the close homologue of the neural adhesion cell LI (CHL1) display alterations in the emotional reactivity and motor coordination. Behav Brain Res 147:31-39.

Sakurai K, Migita O, Toru M, Arinami T (2002) An association between missense polymorphism in the close homologue of L1 (CHL1, CALL) gene and schizophrenia. Mol Psychiatry 7:412-415. 